\title{
Scour below a subsea Pipeline in Time Varying Flow Conditions
}

\author{
Qin Zhang ${ }^{1,2, *}$, Scott Draper ${ }^{2,3}$, Liang Cheng ${ }^{2}$, Hongwei $\mathrm{An}^{2}$ \\ ${ }^{1}$ School of Engineering, Ocean University of China, No.238 Songling Road, Qingdao, 266100, Shandong, China \\ ${ }^{2}$ School of Civil, Environmental and Mining Engineering, University of Western Australia, 35 Stirling Highway, Crawley \\ WA 6009, Australia \\ ${ }^{3}$ Centre for Offshore Foundation Systems, University of Western Australia, 35 Stirling Highway, Crawley WA 6009, \\ Australia
}

${ }^{*}$ Corresponding author. Email: zhangqin200000@gmail.com; Tel.: 8653266781550. Tax: +8653266781550.

\begin{abstract}
This paper presents results of an experimental investigation into the time scale of local scour and backfill for a subsea pipeline in changing flow conditions, modelled as two consecutive but different flow conditions and as uniformly increasing flow velocities. Unidirectional current flow, waves and combined waves and current flow are all considered. Based on the results of the experiments, effective time scales of the scour and backfill are quantified and algorithms to predict the scour process in changing flow conditions are derived by accumulating the effects of the different flow conditions. It is found that these algorithms may be used to predict the scour observed in the experimental data reasonably well.
\end{abstract}

Keywords: Time scale; Changing flow; Sediment transport; Subsea pipelines

\section{Introduction}

Considerable progress has been made in the area of scour around subsea pipelines and cables in the past four decades due to the rapid growth of the offshore oil and gas industry and the offshore renewable energy industry (including, for example the development of additional offshore wind farms).

Most early investigations into local scour below subsea pipelines focused on a single flow conditions (i.e. the flow condition did not change during scour). These investigations have included two-dimensional physical model experiments to measure the extent and rate of scour in steady current [1-12] waves [13-15] and combined waves and current $[16,17]$. The three-dimensional local scour below a rigid pipeline has also been investigated experimentally in steady current $[18,19]$, waves and combined waves and current [20]. In 
addition to these experimental investigations, in recent years, various numerical models for predicting twodimensional scour processes have also been developed [21-29].

However, despite these earlier studies, scour development under time-varying flow conditions is arguably of more concerned for offshore pipeline design. This is because scour development may be most critical, for example, during the development of a storm in which seabed velocities are changing. Several researchers have therefore investigated scour around pipelines and other marine structures in time-varying flow conditions. For example, Fredsøe and Sumer [12] have performed experiments in waves only conditions to investigate the variation in scour development under a subsea pipeline following a change in wave climate. For this scenario they concluded that the final equilibrium scour depth is determined only by the final wave climate. More recently, Whitehouse [30] has suggested a time-stepping approach to predict the scour development in time-varying flow conditions. This approach is similar to that proposed by Briaud and Chen [31] to predict the scour depth at a cylindrical bridge pier for a random velocity-time history and multilayer soil stratigraphy. Harris and Whitehouse [32] have also used a similar modelling approach to development an engineering model (denoted as a 'step' model) to predict the development of scour through time around an offshore structure under current, waves and combined waves and current flow. Draper and An [33] investigated the stability of subsea pipelines during large storm flow conditions theoretically and experimentally. Most recently, Hong and Chiew [34] have compared different time dependent pier scour models under unsteady flow conditions. Based on each of these earlier studies it appears that a time-stepping approach may provide a reasonable model to capture changes in scour during time varying flow conditions. However, for pipelines this type of model has not yet been validating through comparison with experimental data for time varying waves and combined waves and current conditions.

Zhang and Draper [35] proposed an improved formula for predicting the time development of scour depth and a universal empirical formula for time scale of scour below subsea pipelines under current only, waves only and combined waves and current flow conditions. In this paper, this model is used as a starting point to develop algorithms to predict scour development in multiple independent flow conditions and uniformly increasing (ramp-up) flow conditions using a step model. To this end, a predictive method is described, and it is compared and validated against experimental data.

\section{Experimental setup}

\section{$2.1 \quad$ O-tubes}

The experiments undertaken in this investigation were performed in the O-tube flumes at The University of Western Australia. The O-tube flumes are fully enclosed recirculating water tunnels with a rectangular 
test section and a propeller-type pump driven by a motor. Two different size O-tubes were employed in this study, the large O-tube (LOT) and the mini O-tube (MOT) respectively.

The test section of the LOT is $17.6 \mathrm{~m}$ in length, $1.4 \mathrm{~m}$ in depth and $1.0 \mathrm{~m}$ in width (a sketch of the facility and model pipe is drawn in Fig. 1). A honeycomb laminator is installed at each end of the test section to reduce the level of turbulence. The LOT is able to generate a maximum steady current velocity of up to 3 $\mathrm{m} / \mathrm{s}$ and an oscillatory flow velocity of up to $1-2.5 \mathrm{~m} / \mathrm{s}$, respectively, for wave periods of 5-13 $\mathrm{s}$. By controlling the rotation direction and speed of the impeller using LABVIEW software on a local computer, the facilities are able to generate time-varying combined steady current and/or regular or irregular oscillatory flow. A detailed description of the LOT facility and its capabilities can be found in An and Luo [36]. A model pipeline with a diameter of $196 \mathrm{~mm}$ was used in the LOT tests, which was rigidly fixed at the centre of the test section (the test section is approximately $88 \mathrm{D}$ in length) and extended across the full width of the test section. The sediment used in the LOT experiments was silica sand with median grain size of $d_{50}=0.24$

$\mathrm{mm}$ and a geometric standard deviation of $\sigma_{g}=\sqrt{d_{84} / d_{16}}=1.37$. The particle size distribution is shown in Fig. 2. The sediment was filled in the middle of the test section, covering a length of $15.7 \mathrm{~m}$ and a depth of between $0.3 \mathrm{~m}$ and $0.7 \mathrm{~m}$ (the deeper section covering approximately $1 \mathrm{~m}$ in length either side of the model pipe).

The MOT facility is approximately 5 times smaller than the LOT. The MOT facility is $2.5 \mathrm{~m}$ in breadth, $0.3 \mathrm{~m}$ in height and $6.4 \mathrm{~m}$ in length. The MOT test facility comprises a motor-impeller system, unplasticized polyvinyl chloride (uPVC) tube sections, two honeycomb transitions at each end of the test section, and one straight test section (the main components are indicated in Fig. 3). The diameter of the uPVC tube is $0.17 \mathrm{~m}$, and there is a tapered section of $0.4 \mathrm{~m}$ in length to connect the circular uPVC tube to each end of the rectangular test section. A model pipeline with a diameter of $D=50 \mathrm{~mm}$ was used in the tests. The model pipeline was rigidly fixed in the middle of the working section, and its surface was smooth. The test crosssection of the MOT is $0.2 \mathrm{~m}$ by $0.3 \mathrm{~m}$, with a length of $1.8 \mathrm{~m}$ (approximately $36 \mathrm{D}$ in length). The bottom $0.11 \mathrm{~m}$ of the working section was filled with sediment. The same sediment as that used in the LOT test was used in the MOT tests.

\subsection{Velocity measurements}

A SonTek Acoustic Doppler velocimeter (ADV) was used to measure the velocity at a sampling rate of 50 Hz. For steady current only flow conditions, the velocity profile across the depth was measured at $2 \mathrm{~m}(10 \mathrm{D})$ upstream of the model pipeline in the LOT. The velocity at each measurement point was obtained by averaging the data over $6 \mathrm{~min}$. The measured velocity profiles were found to agree well with a logarithmic distribution.

For waves only, as well as combined waves and current, flow conditions, the ADV was located centrally 2 $\mathrm{m}(10 \mathrm{D})$ upstream of the model pipeline and $0.1 \mathrm{~m}$ above the initially flat seabed in the LOT. The ADV 
monitored the flow for at least 50 cycles during each experiment, and the period-averaged orbital velocity was estimated using the phase ensemble averaging method [37]

$$
\bar{u}(\omega t)=\frac{1}{N} \sum_{i=1}^{N} u\left(\omega\left(t+(i-1) T_{w}\right)\right),
$$

where $N$ is the number of cycles of the oscillating flow, $T_{w}$ is the oscillatory flow period, $\omega$ is the angular frequency of the oscillating flow and $t$ is the time. In this study, velocity time series were generated in the form of

$$
U_{w c}=U_{w} \sin (\omega t+\varphi)+U_{c},
$$

where the oscillatory flow component $U_{w}$ and current component $U_{c}$ quoted herein have been calculated based on the least square difference between Eq. (2) and the period-averaged velocity from Eq.(2).

For increasing (ramp-up) flow condition in unidirectional currents the ADV was also located at the same point as that described above for the waves only and combined waves and current flow condition test. The ramp-up rate $a_{s}$, or acceleration, was calculated from the least square difference between the measured data and the following formula

$$
u(t)=a_{s} U_{c, \max } t
$$

where $U_{c, \max }$ represents the peak current velocity.

For ramp-up waves only and ramp-up combined waves and current flow conditions, the ADV was again located at the same point as that used for the waves only and combined waves and current flow condition test. The ramp-up rate $a_{s}$, as well as the peak oscillatory flow component $U_{w, \max }$ and the current component $U_{c, \max }$ were calculated from the least square difference between the measured data and the following equation

$$
u(t)=a_{s}\left(U_{w, \max } \sin (\omega t+\varphi)+U_{c}\right) t
$$

\subsection{Scour depth and scour profile}

To monitor the scour depth in the LOT a $2 \mathrm{~mm}$ thin steel probe with marked scales was fixed to the bottom of the model pipeline. This probe extended to the base of the working section. The evolution of the scour depth during the scour process could be measured from outside the glass wall by directly reading from this probe. The probe was fixed $250 \mathrm{~mm}$ away from the glass side wall to achieve a clear view of the scale on the probe and to avoid boundary effects at the wall of the working section.

Scour profiles were also obtained from video images recorded during the LOT and MOT tests. The final scour profile of each experiment in the LOT was also scanned using a handheld three-dimensional (3D) scanner based on Microsoft Kinect. The 3D profile is captured by an infrared (IR) emitter and an IR depth sensor equipped in the scanner. The emitter emits infrared light beams and the depth sensor reads the IR beams reflected back to the sensor. The reflected beams are converted into depth information measuring the 
distance between an object and the sensor. The resolution of the resulting 3D depth image is up to $640 \times$ 480 pixels and the frame rate is up to 30 frames per second. The resolution of the infrared camera is determined by the distance between the sensor and the seabed. In this study, the maximum distance between the $3 \mathrm{D}$ scanner and the seabed is below $1 \mathrm{~m}$. According to Khoshelham and Elberink [38] investigation, the precision of the 3D scour profile data is approximately $2 \mathrm{~mm}$. The 3D handheld scanner was calibrated by a known scale (length, width and height) reference object, and then the precision was subsequently confirmed. Based on this calibration it was determined that the error in the scanned profile was less than $4 \mathrm{~mm}(2.7 \% \mathrm{D})$ for the LOT tests.

The final scour profile in the MOT was measured using a SICK Ranger 3D camera with $\pm-0.1 \mathrm{~mm}$ accuracy. Using laser triangulation, the 3D camera is able to measure the three-dimensional shape of the scanned area, and it sends the measurement results to a PC for further processing. Before the tests, the 3D laser camera was calibrated by using a reference object.

\subsection{Test performed}

Experiments under consecutive flow conditions were conducted in the LOT. Each of this type of experiment was divided into two stages. The first stage started from a flat seabed, with no gap/embedment between the pipeline and seabed. The pipeline was fixed in position and the test was run until scour reached an equilibrium conditions. For the second stage of the test, the pipeline was again held fixed in position, but a different flow condition was introduced until a new equilibrium scour profile was reached. At the end of each stage the scour profile was scanned by the handheld 3D camera.

The ramp-up experiments were conducted in the MOT facility. Each ramp-up experiment consisted of a ramp-up stage and a constant flow stage. The test was started with a flat seabed and no gap between the pipeline and the seabed. Ramp-up flow conditions were then introduced for a fixed period of time. Following this, the pipeline was maintained at this original position, and the peak flow was held constant for a fixed period of time.

\subsection{Test conditions}

The conditions and results of the experiments under consecutive flow conditions are summarized in Table 1. Similarly, the conditions and results of the ramp-up experiments conducted in the MOT are summarized in Table 2.

For the steady current experiments listed in Table1 and Table2, $U_{c}$ is the undistributed current velocity measured at a height above the seabed that was level with the centre of the pipeline.

The pipeline Reynolds number in unidirectional current is defined as:

$$
R e_{c}=\frac{U_{c} D}{v} \text {. }
$$


The viscosity of water is taken to be $1 \times 10^{-6} \mathrm{~m}^{2} / \mathrm{s}$ throughout.

Likewise, the Shields parameter in unidirectional current $\theta_{c}$ has been computed according to:

$$
\theta_{c}=\frac{u_{* c}^{2}}{g(s-1) d_{50}}
$$

where $u_{* c}$ is the current friction velocity, calculated assuming a logarithmic velocity profile

$$
U_{c}(z)=\frac{u_{* c}}{\kappa} \ln \left(\frac{z}{z_{0}}\right),
$$

where $z_{0}$ is the bed roughness length and $\kappa$ is von Karman's constant $(=0.441)$. Following Soulsby [39], the bed roughness length $\mathrm{z}_{0}$ has been estimated using the expression of Christoffersen and Jonsson [40]:

$$
z_{0}=\frac{k_{s}}{30}\left[1-\exp \left(\frac{-u_{* c} k_{s}}{27 v}\right)\right]+\frac{v}{9 u_{* c}},
$$

where $v$ is the kinematic viscosity of water and $k_{s}$ is the Nikuradse roughness (taken to be $2.5 d_{50}$ [39]).

For the waves only experiments listed in the tables, $U_{w}$ is the maximum orbital velocity (measured at a height above the seabed that was level with the centre of the pipeline), and the pipeline Reynolds number is defined as:

$$
R e_{w}=\frac{U_{w} D}{v}
$$

The Keulegan-Carpenter number is defined as:

$$
K C=\frac{U_{w} T_{w}}{D}
$$

The wave Shields parameter $\theta_{w}$ has been calculated based on Eq.(6), replacing $u_{* c}$ with the wave friction velocity $u_{* w}$

$$
u_{* w}=\sqrt{\frac{f_{w}}{2}} U_{w} .
$$

Here, $f_{w}$ is the friction coefficient and is estimated using the following equations [41]. In the case of a hydraulically rough bed $\left(d U_{f m} / v \geq 10\right)$ :

$$
f_{w}=\left\{\begin{array}{l}
0.04\left(\frac{a}{k_{s}}\right)^{-0.25}, \frac{a}{k_{s}}>50 \\
0.04\left(\frac{a}{k_{s}}\right)^{-0.75}, \frac{a}{k_{s}}<50
\end{array},\right.
$$

where $a$ is the free stream amplitude, given by

$$
a=\frac{U_{w} T_{w}}{2 \pi} .
$$

In the case of a hydraulically smooth bed $\left(d_{50} u_{* w} / v<10\right)$, the variation in the friction factor is approximated by

$$
f_{w}=0.035 R E^{-0.16}
$$


where $R E$ is the amplitude Reynolds number, calculated by

$$
R E=\frac{U_{w} a}{v} .
$$

For the combined waves and current flow conditions, the flow ratio $m$ is defined as:

$$
m=\frac{U_{c}}{U_{c}+U_{w}}
$$

where $U_{c}$ is the current velocity component, and $U_{m}$ is the maximum orbital velocity component.

The maximum Shields parameter-in combined waves and current has been calculated according to:

$$
\theta_{\max }=\frac{\tau_{\max }}{g\left(\rho_{s}-\rho\right) d_{50}}
$$

where the maximum shear stress $\tau_{\max }$ has been according to Soulsby [39]:

$$
\tau_{\max }=\tau_{m}+\tau_{w}
$$

The mean shear stress, $\tau_{m}$, which is dependent on the non-linear waves and current interaction has been estimated following Soulsby [39]:

$$
\frac{\tau_{m}}{\tau_{c}}=1+1.2\left(\frac{\tau_{w}}{\tau_{c}+\tau_{w}}\right)^{3.2},
$$

where $\tau_{c}$ and $\tau_{w}$ are the shear stresses under current only and waves only conditions, respectively.

\section{Continued scour process under time varying flow conditions}

The velocity time history experienced by a pipeline installed on a seabed over many years is quite complex and can include tidal currents, solitons and storms with different return periods. Different flow conditions lead to different scour profiles around the pipe, such as symmetric scour profiles (see Fig. 4 (a)) in waves only flow conditions and antisymmetric scour profiles (see Fig. 4 (b)) in current only and combined waves and current flow conditions. Moreover, even in the same type of flow, different flow intensities lead to various extents of scour.

In combination, a series of different flow conditions and flow intensities will therefore alter the evolution of the scour depth underneath the pipe. The increase of the approaching flow intensity normally causes the sediment transport capacity underneath the pipe to increase. Consequently, the scour depth underneath the pipeline may become deeper, and such a transitional process may be called a continued scour process. We consider this continued scour process in this section, presenting results for both types of experiment where scour was observed to increase (or continue) throughout the experiment. 


\subsection{Two consecutive flow conditions}

To investigate the influence of the increase in approach flow intensity, the case of a sequence of two different, yet constant, flow conditions are examined first. This scenario resembles one step change in flow conditions.

For the time scale of scour below subsea pipelines under current only and waves only regimes, Whitehouse [30] proposed a general formula based on previous investigations in [12] to describe the time development of scour at piles and pipelines:

$$
S(t)=S\left(1-\exp \left(-\left(\frac{t}{T}\right)^{p}\right)\right)
$$

where $T$ is the characteristic time scale of the scour process, and $p$ is a empirical coefficient. Eq.(20) is consistent with the formula proposed by Fredsøe and Sumer [12] when $p=1$. Zhang and Draper [35] conducted a series of physical experiments on scour below subsea pipeline under combined waves and current as well as current only and waves only flow conditions. They found that the best agreement with measured data was achieved when $p=0.6$.

Now, considering each of the two consecutive flow conditions in turn, the scour development for the initial flow condition can be expressed as:

$$
S_{1}(t)=S_{1}\left(1-\exp \left(-\frac{t}{T_{1}}\right)^{p}\right),
$$

where $S_{1}$ and $T_{1}$ are the equilibrium scour depth and time scale corresponding to the first flow condition.

The scour due to the second flow condition develops from the equilibrium scour profile reached after the first flow condition. Therefore, if we adopt a step model the scour depth may be expressed as:

$$
S_{2}(t)=S_{2}\left(1-\exp \left(-\frac{t_{i}+t}{T_{2}}\right)^{p}\right),
$$

where $S_{2}$ and $T_{2}$ are the equilibrium scour depth and time scale corresponding to the second flow condition, and $t_{i}$ is the time elapsed for the second flow condition to achieve the scour depth of the first flow condition. This is calculated as:

$$
t_{i}=T_{2}\left[-\ln \left(\frac{S_{2}-S_{1}}{S_{2}}\right)\right]^{1 / p} .
$$

For $p=1$, following Fredsøe and Sumer [12], the time elapsed $t_{f i}$ is therefore

$$
t_{f i}=-T_{f 2} \ln \left(\frac{S_{2}-S_{1}}{S_{2}}\right) .
$$

Here, $t_{f i}$ is the time corresponding to $p=1$, and $T_{f 2}$ represents the characteristic time scale based on $p=$ 1.

For $p=0.6$, the time elapsed $t_{p i}$ is 


$$
t_{p i}=T_{p 2}\left[-\ln \left(\frac{S_{2}-S_{1}}{S_{2}}\right)\right]^{5 / 3} .
$$

Here, $t_{p i}$ is the time corresponding to $p=0.6$, and $T_{p 2}$ represents the characteristic time scale based on $p=0.6$.

We now compare Eq. (21) and Eq. (22) with the experimental results for the LOT tests LS1-1, LS2-1, LS3-1 and LS4-1 in Table 1. All these four tests were started from a combined waves and current flow climate and then followed by steady current (LS1-2), combined waves and current (LS2-2) or waves only (LS3-2 and LS4-2) flow conditions respectively.

The scour depth time histories during the whole process, including the scour process of the first stage and the scour process of the second stage, are plotted in Fig. 5. In each sub-figure, the predicted curves in the first stage are based on Eq. (21) with $p=1$ (the dashed line) and $p=0.6$ (the solid line); likewise, the predicted curves in the second stage are based on Eq.(22).

For $p=1$, the non-dimensional time scale $T_{f}^{*}$ was calculated using the empirical formula represented by Fredsøe and Sumer [12] under current only and waves only flow conditions:

$$
T_{f}^{*}=\frac{1}{50} \theta^{-5 / 3},
$$

where $\theta$ is the Shields parameter. In this study, the Shields parameter is replaced by the current Shields parameter $\theta_{c}$ in steady current, while in waves only flow conditions, it is replaced by the maximum wave Shields parameter $\theta_{w}$; in combined waves and current it is replaced by the maximum Shields parameter $\theta_{\max }[42]$. The time elapsed to reach the equilibrium scour depth in the second flow condition was calculated using Eq.(24).

For $p=0.6$, the non-dimensional time scale was calculated using the empirical formula proposed in [35]:

$$
T_{p}^{*}=0.016 \theta^{-1.5}
$$

The time elapsed to reach the equilibrium scour depth in the second flow condition was calculated using Eq.(25).

The results in Fig. 5 show that for experiments LS3 and LS4, in particular, there is some disagreement initially between the measurements and predictions at the start of the second stage of the scour process. This occurs because the scour hole must grow wider with the new flow condition, before growing deeper. However, this disagreement is not significant and the step model predicts the measurements reasonably well across the majority of the scour development for all four experiments.

For completeness, Fig. 6 illustrates the time development of the seabed profile in the second flow condition for each of the four experiments. It can be observed that the bed profile changes dramatically from the equilibrium scour profile reached in the first flow condition. Furthermore, during the initial stages of scour, the scour profile transforms quite fast; for instance, not only does the scour depth underneath the pipeline increase fast, but the rudiment of the second flow scour profile is also formed quickly. Then, as 
time elapses, the scour rate around the pipeline gradually slows down and the scour depth underneath the pipeline slowly increases towards the characteristic scour profile around the pipeline corresponding to the second flow condition. Finally, after sufficient time, the equilibrium profile is reached, as shown in Fig. 7.

\section{2 'Ramp-up' flow conditions}

The second type of continued scour process that has been simulated is a uniformly increasing flow condition, or a 'ramp-up' flow. This scenario is important to understand because, in practice, it can be used to simulate the ramp-up phase of a storm. The whole period of a storm normally contains three stages, the ramp-up stage, the peak and the ramp-down stage. In this section, the first two stages during a whole period of a storm are considered.

As noted in the introduction, Whitehouse [30] reported a methodology for predicting the change in scour development in an unsteady flow over a small time $\Delta t$. This method states that

$$
\Delta S=\frac{d S}{d t} \Delta t
$$

Assuming that the scour development with time can be defined by Eq.(20), then the scour increment during any time step can be calculated by

$$
\frac{d S}{d t}=\frac{p\left(S_{n}-S_{i}\right)}{T_{n}\left[-\ln \left(\frac{S_{n}-S_{i}}{S_{n}}\right)\right]^{\frac{1}{p}-1}},
$$

where $S_{n}$ is the equilibrium scour depth corresponding to the increased flow condition for each increment, $S_{i}$ is the scour depth that has already been reached, and $T_{n}$ is the time scale corresponding to $S_{n}$. It should be noted that $S_{n}$ is regarded as the ultimate final scour depth, following[30].

For $p=1$, Eq.(29) can be simplified to

$$
\frac{d S}{d t}=\frac{S_{n}-S_{i}}{T_{n}}
$$

For $p=0.6$, Eq.(29) can be written as:

$$
\frac{d S}{d t}=\frac{0.6\left(S_{n}-S_{i}\right)}{T_{n}\left[-\ln \left(\frac{S_{n}-S_{i}}{S_{n}}\right)\right]^{2 / 3}} .
$$

Taking a ramp-up current case as an example, if the current velocity increases at a constant rate of $a_{s}(\mathrm{~m} /$ $s^{2}$ ), the velocity time history can be divided into many time steps. If the step is small enough, the current flow can be roughly regarded as quasi-steady in each time step. Furthermore, if the change in flow occurs gradually, there is sufficient time for the scour depth to grow together with the scour profile. This means that the disagreement observed at the start of the second stage for the consecutive flow experiments (see Fig. 5; LS3 and LS4) is avoided. Consequently, the equilibrium scour depth in each time step can be estimated using the empirical equation presented in [1] based on the average velocity in each step, namely, 


$$
S_{c}=0.972\left(\frac{U^{2}}{2 g}\right)^{0.2} D^{0.8}
$$

The time scale for each time step is dependent on the current Shields parameter, corresponding to the current velocity in each time step. For $p=1$, the dimensionless time scale $T_{f}^{*}$ was calculated via Eq.(26), and the scour depth increment in each time step was calculated via Eq.(30). Meanwhile, for $p=0.6$, the dimensionless time scale $T_{p}^{*}$ was calculated via Eq.(27), and the scour depth increment in each time step was calculated via Eq.(31). Fig. 8 (a) shows the measured velocity time history for a ramp-up current (MC-1) followed by a steady current (MC-2). Fig. 8 (b) shows the measured scour depth varying with time under such a velocity time history and the curves predicted using the above method. The predicted curve with $p=$ 0.6 shows reasonable agreement with the experimental data at the initial stage of the ramp-up current, but starts to overestimate the scour rate after the current velocity exceeds $0.45 \mathrm{~m} / \mathrm{s}$.

Fig. 9 (a) shows the measured velocity for the waves only ramp-up case (MW-1) and the peak wave only case (MW-2). The method used to predict the scour development with time for this case was similar to that used for the current ramp-up case. However, there were two modifications: (i) the time interval and (ii) the equilibrium scour depth. For the waves only ramp-up flow the time interval was set at one wave time period or several wave time periods, whilst the equilibrium scour depth in each time step was calculated in terms of the $\mathrm{KC}$ number using the empirical formula [13],

$$
S_{w}=0.1 \sqrt{K C} \text {. }
$$

The $K C$ number corresponds to the wave flow condition that is relevant in each time step. Fig. 9 (b) shows the measured scour development time history corresponding to the measured velocity in Fig. 9 (a). The two predicted curves show a similar trend to the experimental data. Moreover, the predicted curve with $p=0.6$ has a better fit to the measured data than the curve with $p=1$.

For the combined waves and current ramp-up case, the time interval was also set to the wave time period or several wave time periods. The equilibrium scour depth in each time step was estimated using the empirical formulae proposed in [35],

$$
S_{w c}=\left(S_{c}^{2}+S_{w}^{2}\right)^{0.5}
$$

Here, $S_{c}$ represents the equilibrium scour depth corresponding to the current component obtained by Eq.(32). Meanwhile $S_{w}$ is the equilibrium scour depth corresponding to the wave component, which can be calculated by Eq.(33).

Fig. 10 (a) shows the measured velocity for the ramp-up combined waves and current case (MWC-1) and the steady peak combined waves and current case (MWC-2). The corresponding measured scour depth varying with time and the predicted curves based on the above method are shown in Fig. 10(b). Both predicted curves have good agreement with the experimental data during the ramp-up stage, but they underestimate 
the final equilibrium scour depth. Comparing the two predicted curves, the curve with $p=0.6$ collapses slightly better to the experimental data than the curve with $p=1$ with the experimental data.

Overall, the scour depth development time history has been predicted in the present study reasonably well. The method with $p=0.6$ exhibits a better fit than the method with $p=1$. It should be noted that only three experimental datasets were used to assess the feasibility of the above method. More experiments need to be performed to assess the reliability of the predictive model.

\section{Backfill process}

The previous two sections demonstrated that the equilibrium scour depth is increased due to a change in the flow conditions. However if a scour hole is generated by one flow condition and the second flow has a lower intensity, the scour hole formed in the first step may be backfilled. This is because the decrease in the approach flow intensity causes the sediment transport capacity of the flow underneath the pipeline to drop. Consequently, the sediment may accumulate underneath the pipeline, and the scour depth may become shallower. Such a transitional process is so-called a backfilling process.

For a substantial amount of backfill to develop, a certain amount of time must elapse. This time can be described in terms of the time scale of the backfilling process. To quantify this time scale, a general formula introduced by Sumer and Petersen [43] will be adopted in the present study:

$$
S(t)=S_{\text {final }}+\left(S_{\text {initial }}-S_{\text {final }}\right) \exp \left(-\left(\frac{t}{T_{b}}\right)^{p}\right)
$$

where $T_{b}$ is the time scale of the backfilling process, $S_{\text {initial }}$ is the initial scour depth corresponding to the initial flow condition, and $S_{\text {final }}$ is the final scour depth corresponding to the final flow condition. It should be noted that $p=1$ is adopted in the original form of Eq. (35) in Sumer and Petersen [43].

Two tests related to the backfilling process were performed in the present study to investigate the backfilling process and access the analysis method. These tests included LB1-2 and LB2-2, respectively.

The final equilibrium scour depth and the time scale of the backfilling process were obtained by curve fitting to the experimental data. Due to the limited amount of test data, it is impossible to demonstrate the best fit coefficient $p$ in the present study. Therefore, $p=1$ and $p=0.6$ were chosen as a reference values to predict the scour depth time history. Fig. 11 shows the measured scour depth time history of the backfilling process for tests LB1-2 and LB2-2 and the corresponding initial scour processes (LB1-1 and LB2-1). For the initial scour process (LB1-1 and LB2-1), the predicted curves with $p=1$ and $p=0.6$ were consistent with the curve fitting results in [35]. In the backfilling process, before the scour depth gradually decreases, there is a transitional period for the scour profile around the pipeline to change shape. The transitional period was longer in test LB2-2 than in test LB1-2. 
Fig. 12 shows the bed profile change with time for the two cases. For test LB1-2 (Fig. 12 (a)), the initial scour profile was generated by a combined waves and current flow condition (test LB1-1), and the scour hole was backfilled by a second weaker combined waves and current flow condition (test LB1-2) in the same mean current direction. The bed profile on the upstream side of the pipeline roughly retained its morphology during the whole process, while the profile underneath the pipeline and at the downstream side of the pipeline gradually reduced in depth during the second flow condition until the new equilibrium scour profile was reached. The whole backfilling process took more than $3 \mathrm{~h}$ to accomplish. For completeness, the final 3D scanned scour profiles for LB1-2 are illustrated in Fig. 13 (a) and (b).

For test LB2-2 (Fig. 12 (b)) the initial equilibrium scour profile was also generated by a combined waves and current flow condition, and the second stage of the scour process was then simulated under a steady current flow condition. Furthermore, the mean current direction of the second flow condition was in the opposite direction to the first flow condition. In the scour process of the second flow condition the bed profile on the upstream and downstream sides of the pipeline altered dramatically, with one side raised and the other reduced. A new bed morphology corresponding to the opposite direction steady current was formed. During the bed profile shift, the scour depth underneath the pipeline was unstable. However, after the bed profile shift was completed the scour depth underneath the pipeline began to decrease steadily. The final 3D scour profile for LB2-2 is plotted in Fig. 13 (c). The observation of sand ripples implies that the current flow was very weak, but after sufficient time, the equilibrium scour profile consistent with that observed in current only conditions is eventually formed.

Based on the present experiments, it appears that the scour profile always transforms from one related to the initial flow conditions to one related to the final flow conditions. This transformation happens simultaneously with the scour depth increase (continued scour process) or decrease (backfilling process). However, if a dramatic change in scour profile needs to be achieved such as in test LB2-2, it may take a long time before the scour depth becomes stable.

\section{Conclusions}

In this paper, local scour below a pipeline has been investigated experimentally for two consecutive flow conditions and uniform ramp-up flow conditions. The following conclusions can be drawn from this investigation:

1. Continued scour beneath a pipeline occurs when the flow climate changes from a relatively weak flow (with small equilibrium scour depth) to a relatively strong flow (with larger equilibrium scour depth). Furthermore, the final scour profile is determined by the final flow condition. 
2. The scour depth development in continued scour processes can be predicted by accumulating scour depth in each successive flow condition.

3. The scour depth and dimensionless time scale empirical formulae obtained in previous papers [12, 35] can be extended to multi-flow conditions and ramp-up flow conditions. The empirical formulae proposed in the previous papers $[12,13,35]$ for the equilibrium scour depth and time scale appear to give good agreement with experiments.

4. The backfilling of a scour hole beneath a pipeline occurs when the flow climate changes from a relatively flow condition conducive to large scour, to a flow condition conducive to relatively small scour. Furthermore, the final scour profile is determined by the final flow condition.

5. The time scale of the backfilling process is completely different from the scour process. The time scale of backfilling is much larger than that of the scour process in the present test results.

6. There is a transformation period in both the continued scour process and the backfilling process. If the overall scour morphology around the pipeline changes due to the second flow condition (i.e. the width and depth change), the transformation can take much more time to accomplish.

\section{Acknowledgements}

This work was supported by an Australian Research Council Discovery Grant (Project ID: DP130104535). The first author would like to acknowledge the support of the Australian Government and the University of Western Australia for providing SIRF and UIS scholarships for a doctoral degree.

\section{Notation}

The following symbols are used in the paper:

$D \quad=$ diameter of the pipeline;

$d_{50}=$ median grain size of bed sediment;

$f_{w} \quad=$ friction coefficient in waves;

$g=$ acceleration due to gravity;

$K C=$ Keulegan-Carpenter number;

$k_{s} \quad=$ Nikuradse roughness;

$N=$ number of cycles of the oscillating flow;

$p \quad=$ empirical coefficient;

$R E \quad=$ amplitude Reynolds number;

$S(t) \quad=$ Time-varying scour depth; 
$S_{1} \quad=$ equilibrium scour depth corresponding to the first flow condition;

$S_{2}=$ equilibrium scour depth corresponding to the second flow condition;

$S_{c}=$ equilibrium scour depth corresponding to the current component at the level of pipeline centre in the combined waves and current flow conditions;

$S_{\text {initial }}=$ initial scour depth corresponding to the initial flow condition;

$S_{\text {final }}=$ final scour depth corresponding to the final flow condition;

$S_{n} \quad=$ equilibrium scour depth corresponding to the increased flow conditions for each increment;

$S_{w} \quad=$ equilibrium scour depth corresponding to the wave component at the level of pipeline centre in the combined waves and current flow conditions;

$S_{w c}=$ equilibrium scour depth in combined waves and current flow condition;

$s \quad=$ relative density of the sediment;

$T=$ characteristic time scale of the scour process;

$T_{1} \quad=$ time scale corresponding to the first flow condition;

$T_{2}=$ time scale corresponding to the second flow condition;

$T_{f 2}=$ characteristic time scale based on $p=1$;

$T_{p 2}=$ characteristic time scale based on $p=0.6$;

$T_{b} \quad=$ time scale of the backfilling process;

$T_{f}=$ characteristic time scale based on Eq. (1);

$T_{p}=$ characteristic time scale based on Eq. (11);

$T_{w} \quad=$ oscillatory flow period;

$T_{f}^{*} \quad=$ non-dimensional time scale based on $p=1$;

$T_{p}^{*} \quad=$ non-dimensional time scale based on $p=0.6$;

$t \quad=$ time;

$t_{i}=\begin{aligned} & \text { time elapsed for the second flow conditions to achieve the scour depth of the first flow } \\ & \text { condition; }\end{aligned}$

$t_{f i}=$ time corresponding to $p=1$;

$t_{p i}=$ time corresponding to $p=0.6$;

$U_{c} \quad=$ current flow velocity;

$U_{c, \max }=$ Maximum velocity in uniformly increasing current flow;

$U_{w} \quad=$ oscillatory flow velocity;

$U_{w, \max }=$ Maximum oscillatory flow velocity in uniformly increasing wave flow;

$U_{w c}=$ combined waves and current flow velocity

$\bar{u} \quad=$ average instantaneous flow velocity; 


$$
\begin{aligned}
u_{* c} & =\text { friction velocity in current; } \\
u_{* w} & =\text { friction velocity in waves; } \\
z_{0} & =\text { bed roughness length } \\
z_{i} & =\text { initial rate of increase of } S(t) ; \\
\alpha & =\text { free stream amplitude; } \\
a_{s} & =\text { ramping rate; } \\
\theta & =\text { Shields parameter; } \\
\theta_{c} & =\text { current Shields parameter; } \\
\theta_{m a x} & =\text { maximum Shields parameter; } \\
\theta_{w} & =\text { wave Shields parameter; } \\
\kappa & =\text { von Karman's constant; } \\
v & =\text { kinematic viscosity of water; } \\
\tau & =\text { shear stress; } \\
\tau_{c} & =\text { current shear stress; } \\
\tau_{m} & =\text { mean shear stress; } \\
\tau_{m a x} & =\text { maximum shear stress; } \\
\tau_{w} & =\text { wave shear stress; } \\
\varphi & =\text { phase; } \\
\omega & =\text { angular frequency of the oscillating flow; }
\end{aligned}
$$




\section{Reference}

[1] Kjeldsen SP, Gjorsvik O, Bringaker K, Jacobsen J. Local scour near offshore pipelines. Second international conference on port and ocean engineering under arctic conditions (POAC). Reykjavik: University of Iceland, Department of Engineering and Science; 1973. p. 308-31.

[2] Bijker E, Leeuwestein W. Interaction between pipelines and the seabed under the influence of waves and currents. Seabed Mech. 1984:235-42.

[3] Mao Y. The interaction between a pipeline and an erodible bed, [Ph.D thsis] 1986, Technical University of Denmark; Denmark.

[4] Chiew YM. Prediction of maximum scour depth at submarine pipelines. J Hydraul Eng. 1991;117:45266.

[5] Moncada-M AT, Aguirre-Pe J. Scour below pipeline in river crossings. J Hydraul Eng. 1999;125:953-8.

[6] Gao F-P, Yang B, Wu Y-X, Yan S-M. Steady current induced seabed scour around a vibrating pipeline. Appl Ocean Res. 2006;28:291-8.

[7] Azamathulla HM, Zakaria NA. Prediction of scour below submerged pipeline crossing a river using ANN. Water Sci Technol. 2011;63:2225-30.

[8] Azamathulla HM, Guven A, Demir YK. Linear genetic programming to scour below submerged pipeline. Ocean Eng. 2011;38:995-1000.

[9] Azamathulla HM, Yusoff MAM, Hasan ZA. Scour below submerged skewed pipeline. Journal of Hydrology. 2014;509:615-20.

[10] Najafzadeh M, Barani G-A, Azamathulla H. Prediction of pipeline scour depth in clear-water and livebed conditions using group method of data handling. Neural Comput Appl. 2014;24:629-35.

[11] Azamathulla H, Mohd. Yusoff MA. Soft computing for prediction of river pipeline scour depth. Neural Comput Appl. 2013;23:2465-9.

[12] Fredsøe J, Sumer BM, Arnskov MM. Time scale for wave/current scour below pipelines. Int J Offshore Polar Eng. 1992;2:13-7.

[13] Sumer BM, Fredsøe J. Scour below pipelines in waves. Journal of Waterway, Port, Coastal, and Ocean Engineering. 1990;116:307-23.

[14] Etemad-Shahidi A, Yasa R, Kazeminezhad MH. Prediction of wave-induced scour depth under submarine pipelines using machine learning approach. Appl Ocean Res. 2011;33:54-9.

[15] Gao FP, Gu XY, Jeng DS, Teo HT. An experimental study for wave-induced instability of pipelines: the breakout of pipelines. Appl Ocean Res. 2002;24:83-90.

[16] Sumer BM, Fredsøe J. Scour around pipelines in combined waves and current. Proc 7th International Conference on Offshore Mechanics Arctic Engineering. Florence, Italy: ASME; 1996. p. 595-602. 
[17] Lucassen R. Scour underneath submarine pipelines, [Master thesis] 1984, Delft University of Technology; Netherlands.

[18] Cheng L, Yeow K, Zhang ZP, Teng B. Three-dimensional scour below offshore pipelines in steady currents. Coast Eng. 2009;56:577-90.

[19] Wu Y, Chiew Y. Three-dimensional scour at submarine pipelines. J Hydraul Eng. 2012;138:788-95.

[20] Cheng L, Yeow K, Zang Z, Li F. 3D scour below pipelines under waves and combined waves and currents. Coast Eng. 2014;83:137-49.

[21] Brørs B. Numerical modeling of flow and scour at pipelines. J Hydraul Eng. 1999;125:511-23.

[22] Li F, Cheng L. Numerical model for local scour under offshore pipelines. J Hydraul Eng. 1999;125:400-6.

[23] Liang D, Cheng L, Li F. Numerical modeling of flow and scour below a pipeline in currents: Part II. Scour simulation. Coast Eng. 2005;52:43-62.

[24] Liang DF, Cheng L. Numerical modeling of flow and scour below a pipeline in currents - Part I. Flow simulation. Coast Eng. 2005;52:25-42.

[25] Zhao M, Cheng L. Numerical modeling of local scour below a piggyback pipeline in currents. $J$ Hydraul Eng. 2008;134:1452-63.

[26] Zhu H, Qi X, Lin P, Yang Y. Numerical simulation of flow around a submarine pipe with a spoiler and current-induced scour beneath the pipe. Appl Ocean Res. 2013;41:87-100.

[27] Zanganeh M, Yeganeh-Bakhtiary A, Abd Wahab AK. Lagrangian coupling two-phase flow model to simulate current-induced scour beneath marine pipelines. Appl Ocean Res. 2012;38:64-73.

[28] Wen F, Jeng DS, Wang JH, Zhou XL. Numerical modeling of response of a saturated porous seabed around an offshore pipeline considering non-linear wave and current interaction. Appl Ocean Res. 2012;35:25-37.

[29] Yeganeh-Bakhtiary A, Kazeminezhad MH, Etemad-Shahidi A, Baas JH, Cheng L. Euler-Euler twophase flow simulation of tunnel erosion beneath marine pipelines. Appl Ocean Res. 2011;33:137-46.

[30] Whitehouse R. Scour at Marine Structures: a manual for practical applications. UK: Thomas Telford; 1998.

[31] Briaud J, Chen H, Kwak K, Han S, Ting F. Multiflood and multilayer method for scour rate prediction at bridge piers. J Geotechn Geoenviron Eng. 2001;127:114-25.

[32] Harris JM, Whitehouse RJS, Benson T. The time evolution of scour around offshore structures. Proc ICE Maritime Eng. 2010;163:3-17.

[33] Draper S, An H, Cheng L, White DJ, Griffiths T. Stability of subsea pipelines during large storms. Philos Trans R Soc Lond A Math Phys Eng Sci. 2014;373.

[34] Hong JH, Chiew YM, Yeh PH. Comparisons of time dependent pier scour models under unsteady flow conditions. Scour and Erosion: CRC Press; 2014. p. 473-81. 
[35] Zhang Q, Draper S, cheng L, An H, Time scale of local scour around pipelines in current/waves and combined waves and current, 2015, University of Western Australia, Perth, Western Australia, [Submitted for publication].

[36] An H, Luo C, Cheng L, White D. A new facility for studying ocean-structure-seabed interactions: The O-tube. Coast Eng. 2013;82:88-101.

[37] Jensen B. Experimental investigation of turbulent oscillatory boundary layers, 1988, Technical University of Denmark; Denmark.

[38] Khoshelham K, Elberink SO. Accuracy and resolution of kinect depth data for indoor mapping applications. Sensors. 2012;12:1437-54.

[39] Soulsby R. Dynamics of marine sands: a manual for practical applications. UK: Thomas Telford; 1997.

[40] Christoffersen JB, Jonsson IG. Bed friction and dissipation in a combined current and wave motion. Ocean Eng. 1985;12:387-423.

[41] Fredsøe J, Deigaard R. Mechanics of coastal sediment transport. Singapore: World Scientific; 1992.

[42] Zhang Q. Some aspects of local scour mechanics around subsea pipelines, 2015, University of Western Australia;

[43] Sumer BM, Petersen TU, Locatelli L, Fredsoe J, Musumeci RE, Foti E. Backfilling of a Scour Hole around a Pile in Waves and Current. J Waterway Port Coast Ocean Eng. 2013;139:9-23. 


\section{List of figures}

- Fig. 1. Sketch of the large O-tube facility.

- Fig. 2. Particle size distribution of the model sediment.

- $\quad$ Fig. 3. Sketch of the mini O-tube facility.

- Fig. 4. Sketch of scour below pipeline. (a) Waves and (b) steady current/combined waves and current.

- Fig. 5. Scour depth development with time: (a) test LS1-1 and LS1-2; (b) test LS2-1 and LS2-2; (c) test LS3-1 and LS3-2; (d) test LS4-1 and LS4-2.

- Fig. 6. Development of bed profile with time for continuing scour process: (a) test LS1-2; (b) test LS2-2; (c) test LS3-2; (d) test LS4-2.

- Fig. 7. Final equilibrium scour profile for continuing scour process: (a) LS1-2 upstream; (b) LS1-2 downstream; (c) LS3-2 upstream; (d) LS3-2 downstream.

- Fig. 8. Ramp-up current velocity time series (tests MC-1 and MC-2): (a) velocity time histories and (b) scour depth development.

- Fig. 9. Ramp-up waves velocity time series (Tests MW-1 and MW-2): (a) velocity time histories; (b) scour depth development.

- Fig. 10. Ramp-up combined waves and current velocity time series (tests MWC-1 and MWC-2): (a) velocity time histories and (b) scour depth development.

- Fig. 11. Flow climate change in two stages: (a) tests LB1-1 and LB1-2 and (b) tests LB2-1 and LB2-2.

- Fig. 12. Development of bed profile with time for backfilling process: (a) test LB1-2 and (b) test LB2-2.

- Fig. 13. Final equilibrium scour profile for backfilling process: (a) LB1-2 upstream and (b) LB1-2 downstream; (c) LB2-2. 


\section{TABLE}

- Table 1. Scour experiments performed in the LOT for two consecutive flow conditions.

- Table 2. Experiments performed in the MOT for ramp-up flow conditions. 


\section{FIGURES}

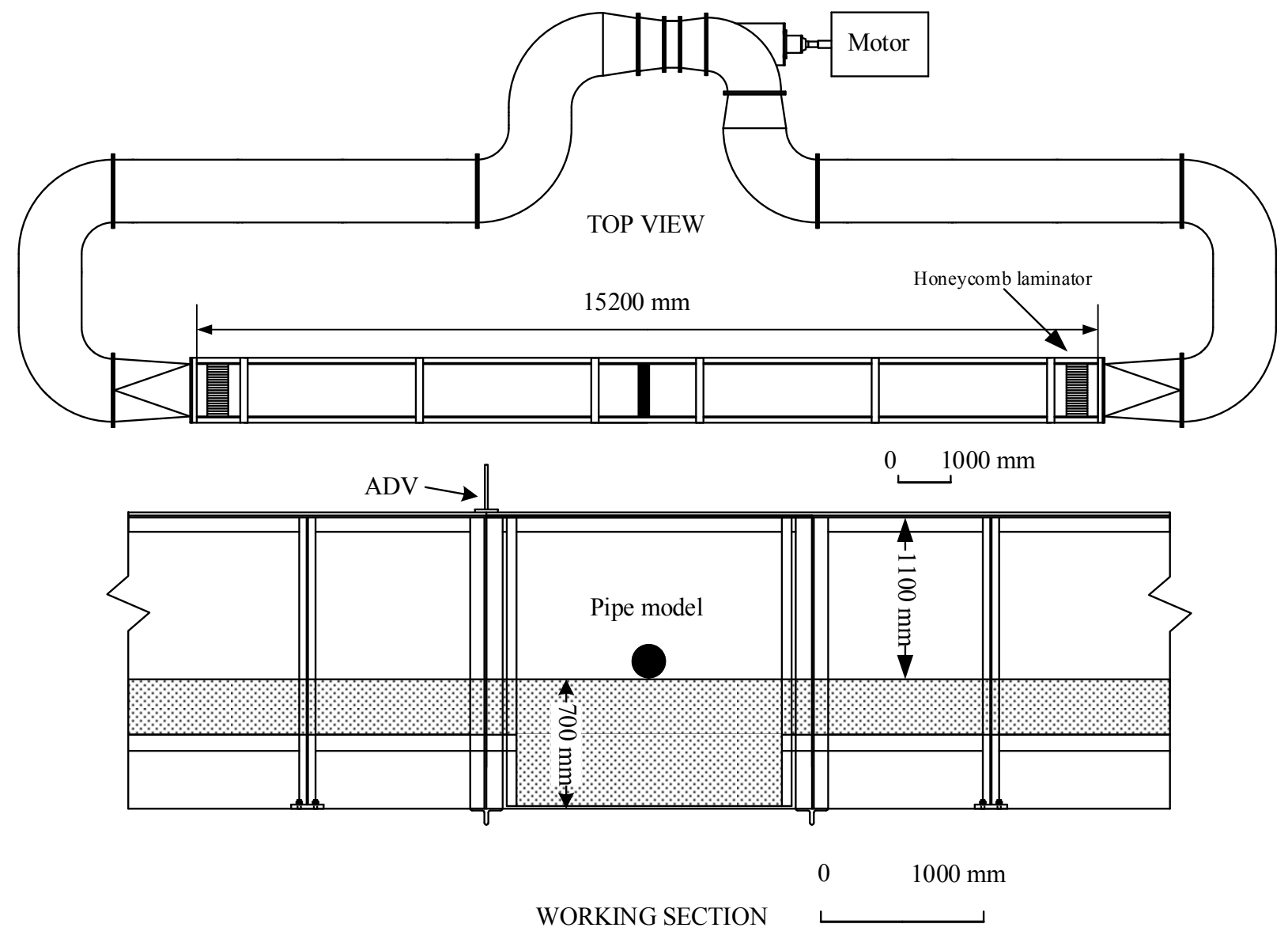

Fig. 1. Sketch of the large O-tube facility 


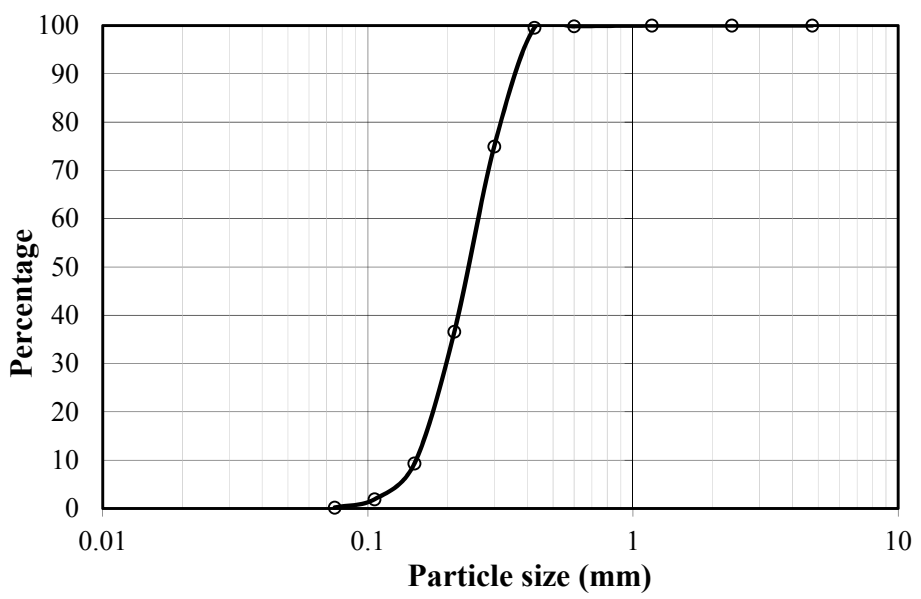

Fig. 2. Particle distribution of the model sediment 


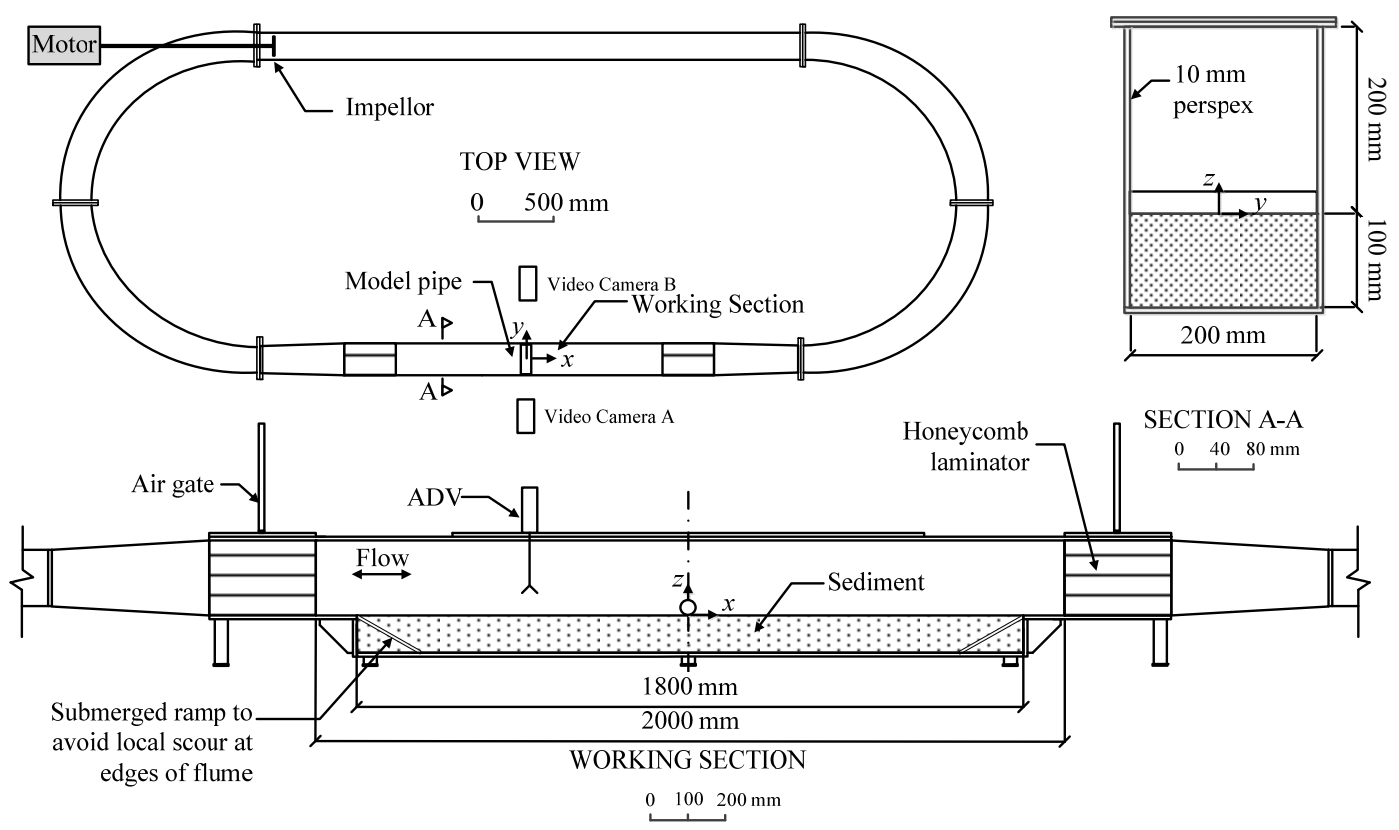

Fig. 3. Sketch of the mini O-tube facility 


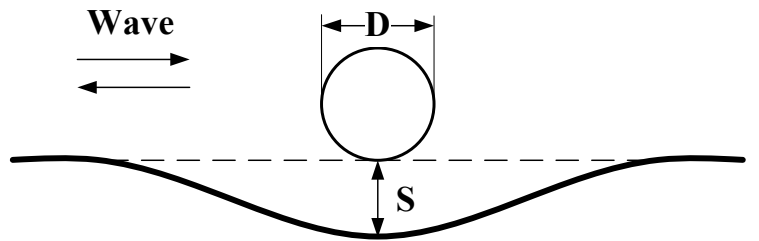

(a) Waves

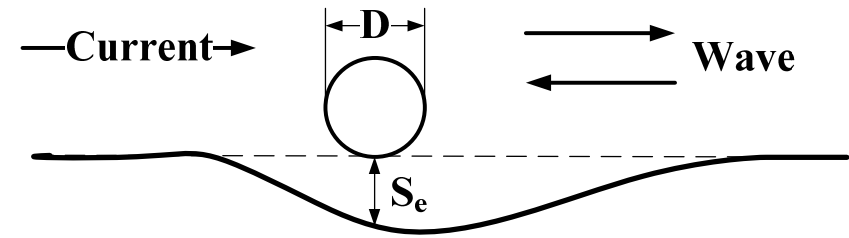

(b) Steady current/combined waves and current

Fig. 4. Sketch of scour below pipeline. (a) Waves and (b) steady current/combined waves and current. 


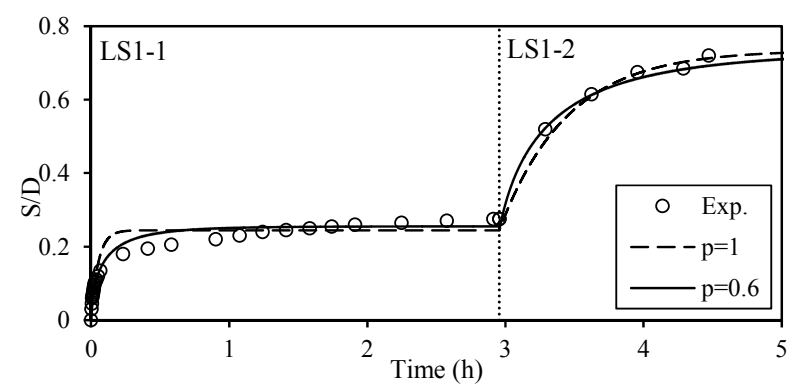

(a) Test LS1-1 and LS1-2

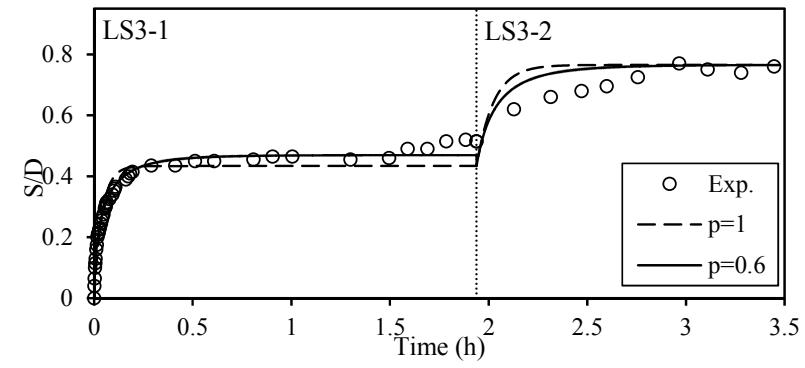

(c) Test LS3-1 and LS3-2

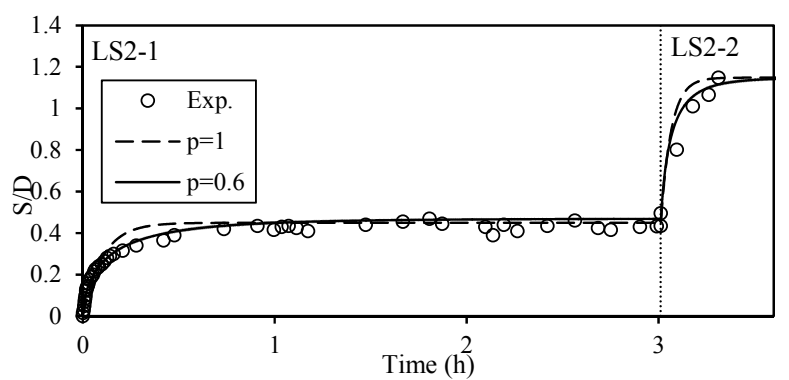

(b) Test LS2-1 and LS2-2

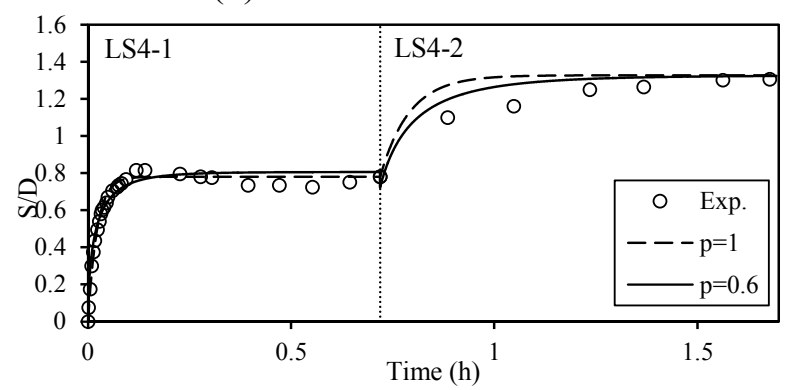

(d) Test LS4-1 and LS4-2

Fig. 5. Scour depth development with time: (a) test LS1-1 and LS1-2; (b) test LS2-1 and LS2-2; (c) test LS3-1 and LS3-2; (d) test LS4-1 and LS4-2. 


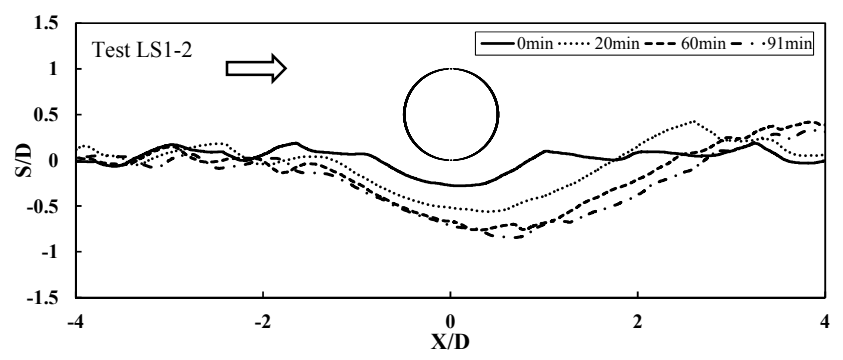

(a) Test LS1-2

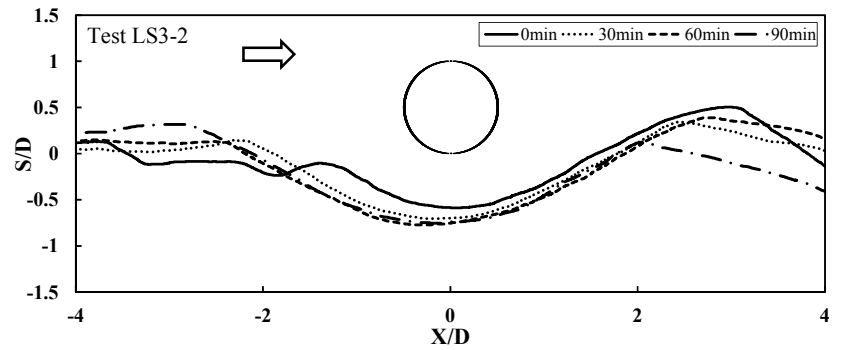

(c) Test LS3-2

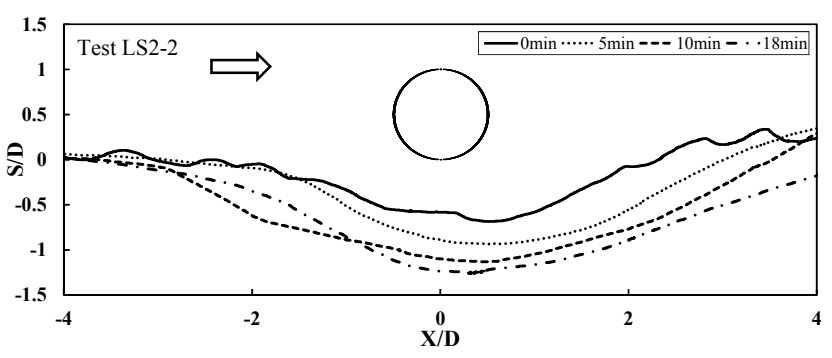

(b) Test LS2-2

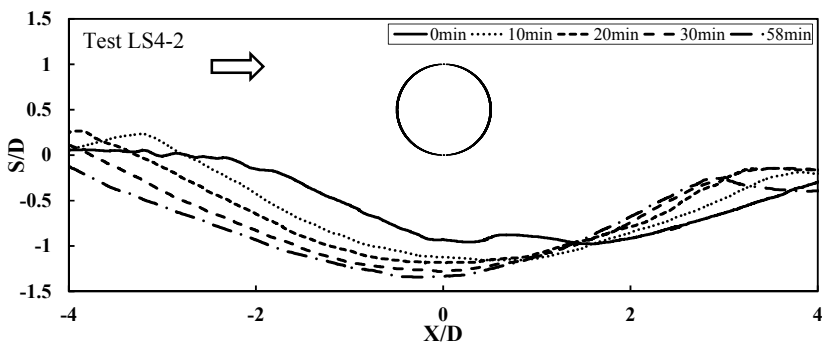

(d) Test LS4-2

Fig. 6. Development of bed profile with time for continuing scour process: (a) test LS1-2; (b) test LS2-2; (c) test LS3-2; (d) test LS4-2. 


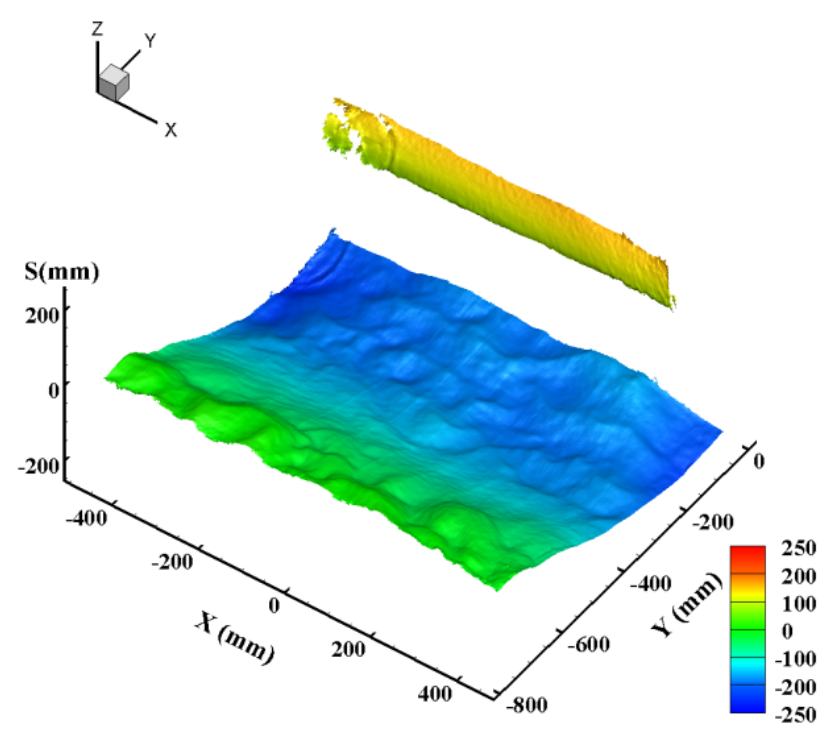

(a) LS1-2 upstream

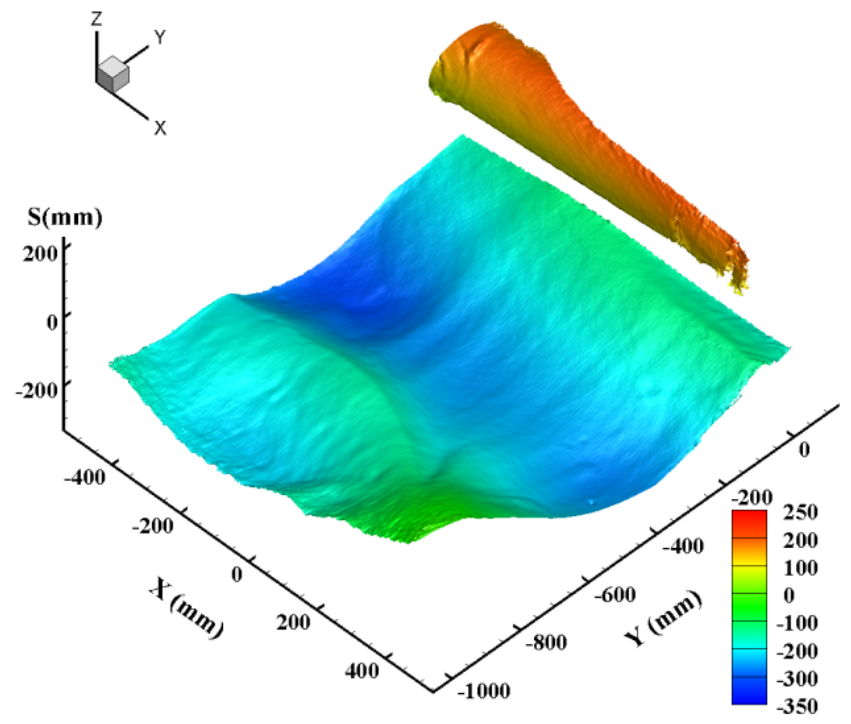

(c) LS3-2 upstream

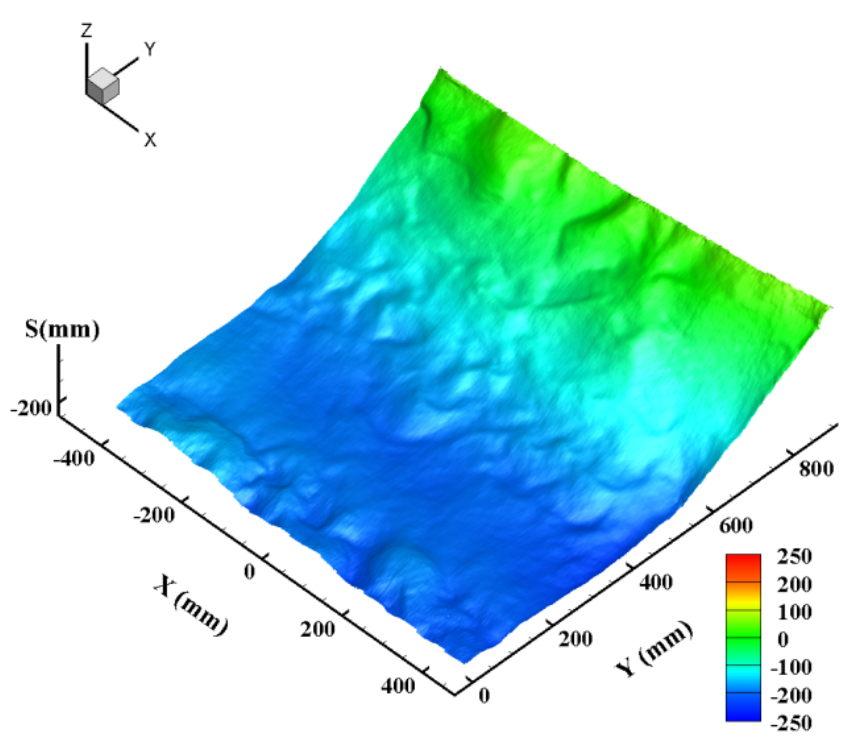

(b) LS1-2 downstream

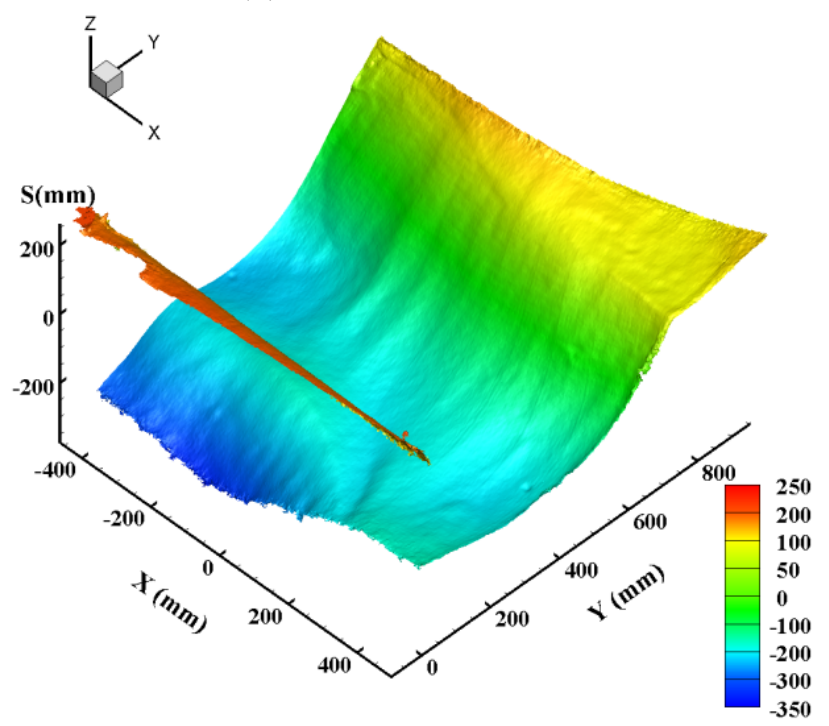

(d) LS3-2 downstream

Fig. 7. Final equilibrium scour profile for continuing scour process: (a) LS1-2 upstream; (b) LS1-2 downstream; (c) LS3-2 upstream; (d) LS3-2 downstream. 


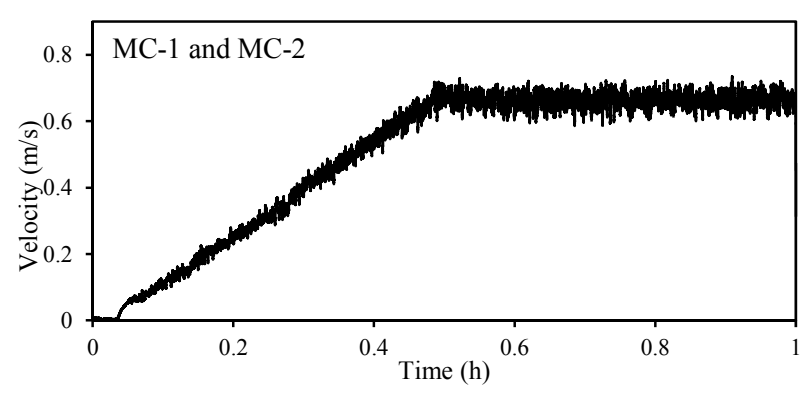

(a) velocity time histories

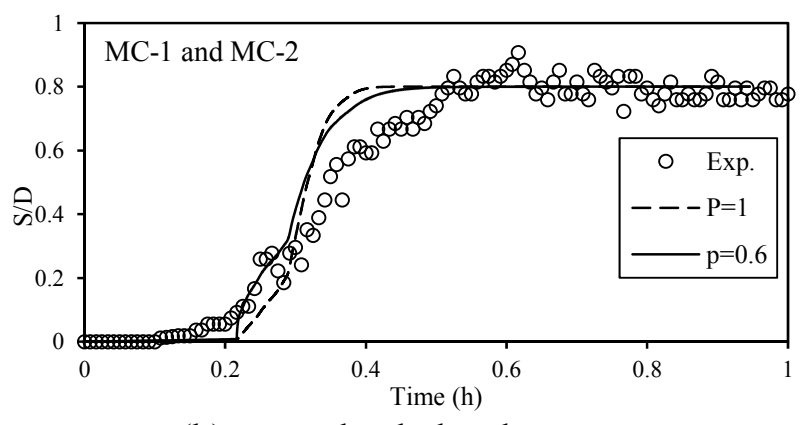

(b) scour depth development.

Fig. 8. Ramp-up current velocity time series (tests MC-1 and MC-2): (a) velocity time histories and (b) scour depth development. 


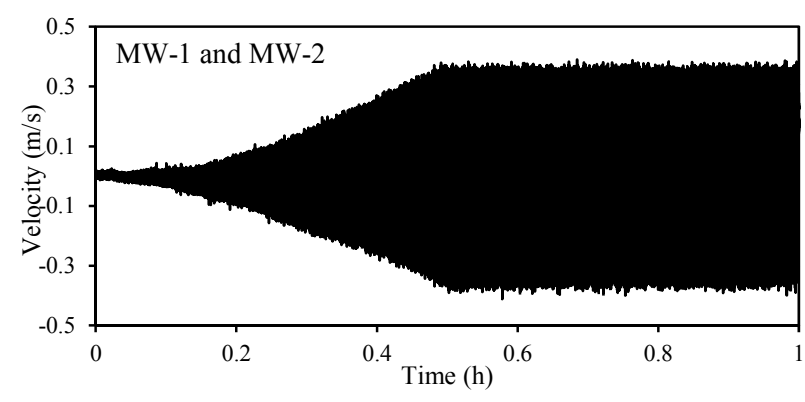

(a) velocity time histories

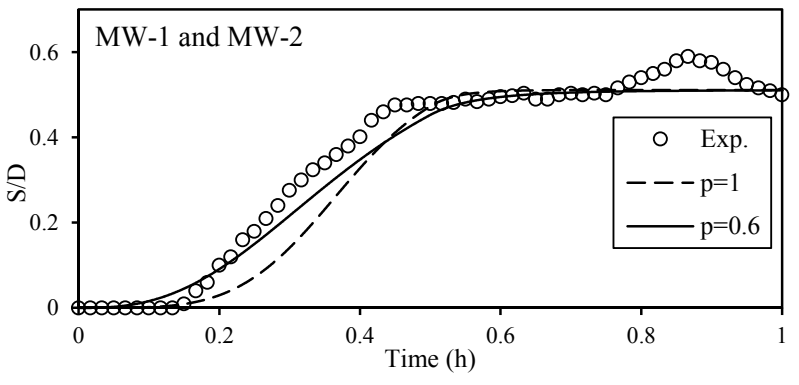

(b) scour depth development

Fig. 9. Ramp-up waves velocity time series (tests MW-1 and MW-2) : (a) velocity time histories and (b) scour depth development. 


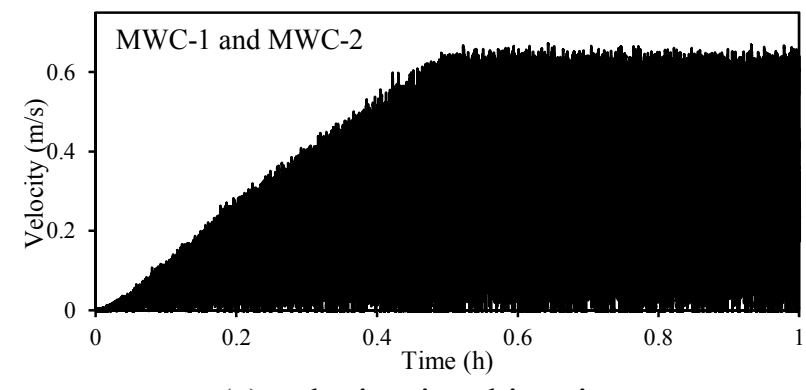

(a) velocity time histories

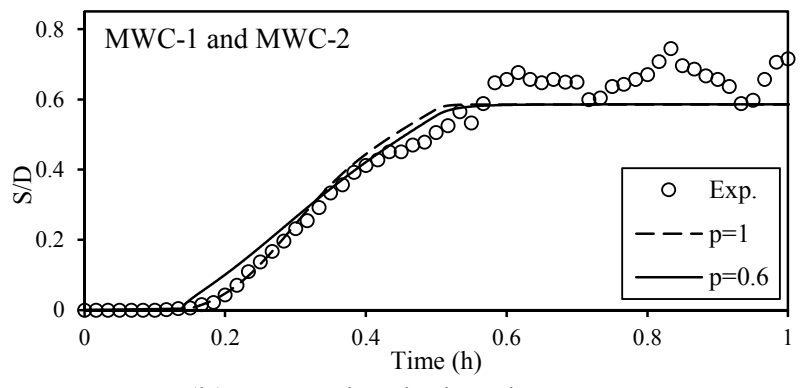

(b) scour depth development

Fig. 10. Ramp-up combined waves and current velocity time series (tests MWC-1 and MWC-2) : (a) velocity time histories and (b) scour depth development. 


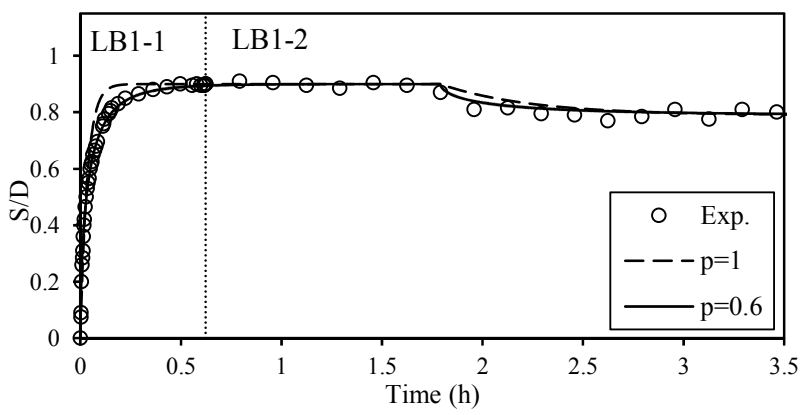

(a) Test LB1-1 and LB1-2

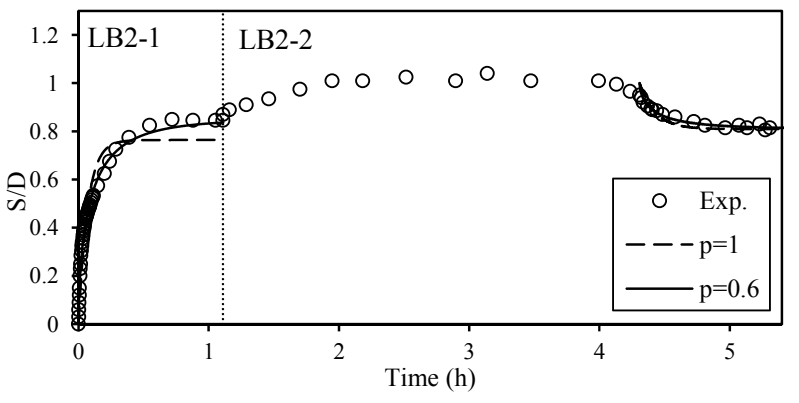

(b) Test LB2-1 and LB2-2

Fig. 11. Flow climate change in two stages: (a) tests LB1-1 and LB1-2 and (b) tests LB2-1 and LB2-2. 


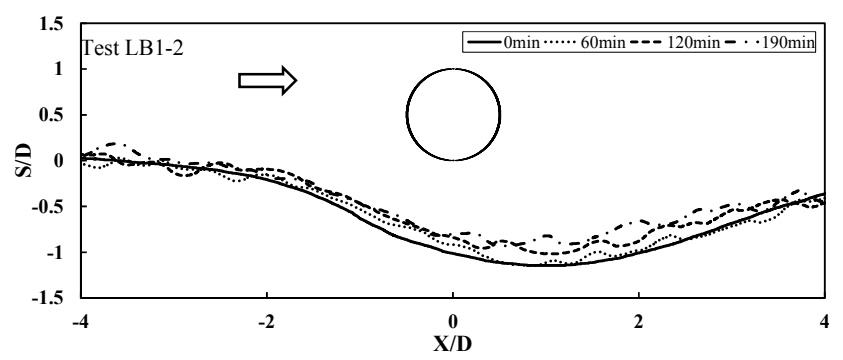

(a) Test LB1-2

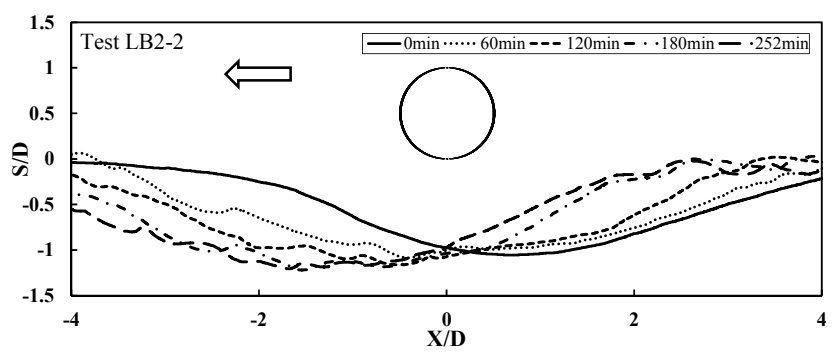

(b) Test LB2-2

Fig. 12. Development of bed profile with time for backfilling process: (a) test LB1-2 and (b) test LB2-2. 


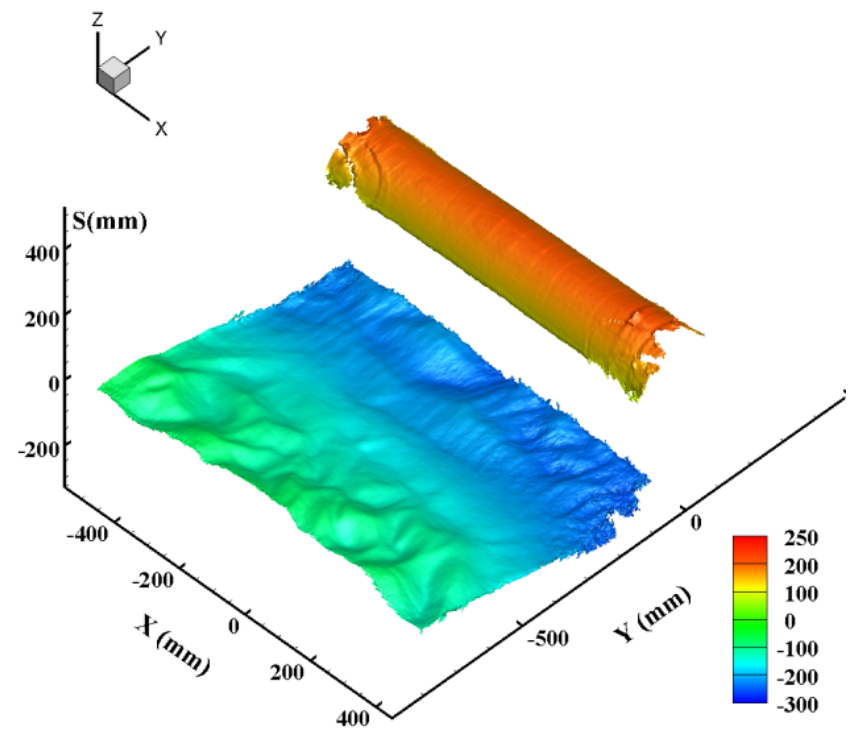

(a) LB1-2 upstream

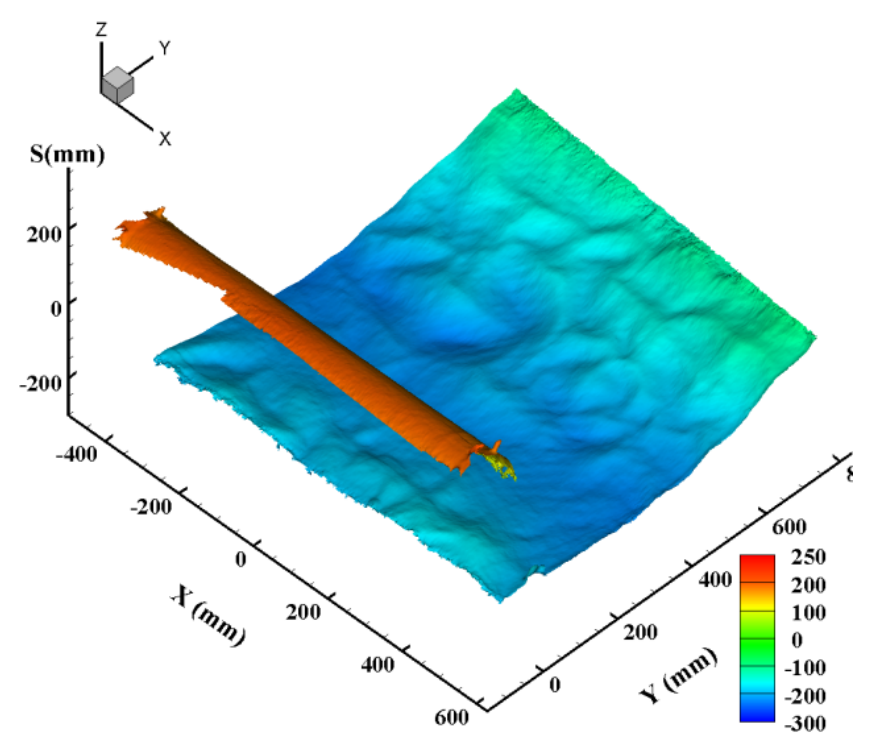

(b) LB1-2 downstream

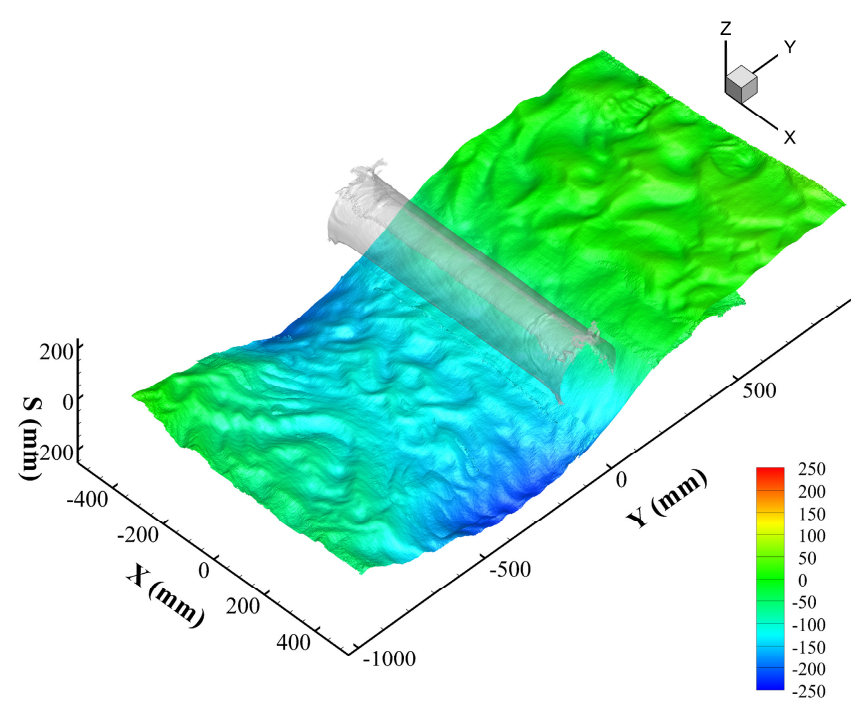

(c) LB2-2

Fig. 13. Final equilibrium scour profile for backfilling process: (a) LB1-2 upstream; (b) LB1-2 downstream; (c) LB2-2. 